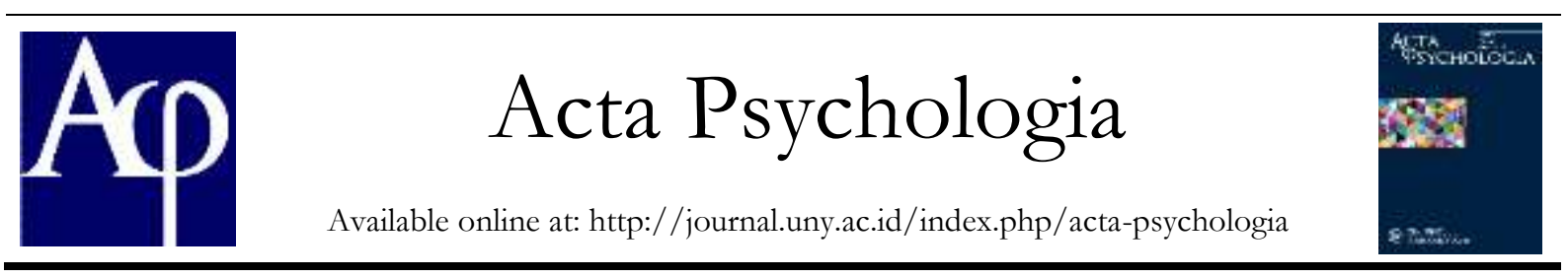

\title{
Efikasi Diri dan Aspirasi Karir Siswa untuk Menjadi Pemain Sepakbola Profesional
}

\author{
Victory Ilham Tamtomo \\ Jurusan Psikologi, Fakultas Ilmu Pendidikan, Universitas Negeri Yogyakarta; \\ Jl. Colombo No. 1 Sleman Yogyakarta, 55281 \\ victorytamtomo@gmail.com
}

\begin{abstract}
Abstrak
Penelitian ini bertujuan untuk: (1) Mengetahui tingkat efikasi diri siswa sekolah sepakbola Persiba, (2) Mengetahui tingkat aspirasi karier siswa sekolah sepakbola Persiba, dan (3) Mengetahui adakah pengaruh efikasi diri terhadap aspirasi karier siswa sekolah sepakbola persiba. Jenis penelitian ini adalah ex-post facto. Subjek penelitian pada penelitian ini berjumlah 51 siswa SSB Persiba. Alat pengumpulan data berupa skala efikasi diri dan skala aspirasi karier. Uji validitas instrumen menggunakan validitas isi dengan expert judgment, sedangkan reliabilitas dihitung dengan menggunakan rumus Alpha Cronbach, dan diperoleh nilai koefisien $\alpha$ sebesar 0,828 pada instrumen efikasi diri dan 0,831 pada instrumen aspirasi karier. Analisis data menggunakan uji regresi sederhana. Hasil penelitian menunjukkan: (1) Efikasi diri siswa sekolah sepakbola Persiba mayoritas berada pada kategori sedang; (2) Aspirasi karier siswa sekolah sepakbola Persiba mayoritas berada pada kategori sedang; (3) Ada pengaruh efikasi diri terhadap aspirasi karier dengan nilai $\beta=0,726 \mathrm{p}<0,05)$. Dengan demikian, variabel efikasi diri dapat mempengaruhi aspirasi karier. Persamaan garis regresi sebesar 19,772 dan sumbangan efektif variabel efikasi diri terhadap aspirasi karier sebesar 51,5\% $\left(\mathrm{R}^{2=}=0,515 ; \mathrm{F}(1,49)=52,035, \mathrm{p}<0.001\right)$
\end{abstract}

Kata Kunci: transmisi nilai, keluarga beda agama

\begin{abstract}
The purpose of this study was to: (1) Determine the self-effication level of students on football school, (2) Determine the career aspiration level of students on football school, and (3) Determine the effect of self-effication on career aspiration students in football school. This type of research is ex-post facto. The Subject in this research were 51 students of Persiba Football School. Data were collected using self effication scale and career aspiration scale. In this research content validity expert judgement was used to test the validity, the reliability is calculated using the Alpha Cronbach, and the coefficient value of $\alpha$ is 0.828 on self-effication instrument and 0.831 on career aspiration instrument. For data analysis this study used simple regression test. The results of this study indicated that: (1) The studens self-effication in Persiba Football School were mostly in moderate or sufficient category; (2) The students career aspiration of Persiba Football School were mostly in moderate category; (3) Career aspiration is affected by self-effication with a value of $\beta=0,726 \mathrm{p}<0,05)$. Thus, the self-effication variable could affect career aspiration. The regression line equation was 19,772 and effective contribution of the self-effication variable to career

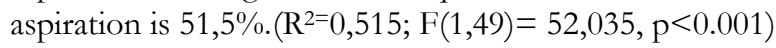

Keywords: transmission of value, multi-religion family.

\section{Pendahuluan}

Olahraga saat ini telah menjadi gaya hidup bagi tiap kalangan masyarakat, berbagai lapisan usia mulai dari usia muda hingga usia lansia tak lepas dari berolahraga. Tidak hanya sebagai gaya hidup, olahraga juga telah menjadi sarana prestasi diri dan juga bidang karier. Salah satu olahraga yang sangat populer saat ini adalah sepakbola, hal ini dikarenakan sepakbola sangat digemari oleh banyak kalangan mulai dari anak-anak, orang dewasa, hingga lansia. Sepakbola saat ini juga tidak mengenal 
gender, baik laki-laki maupun perempuan sama-sama memiliki akses yang sama terhadap sepakbola.

Dengan semakin populernya olahraga sepakbola khususnya di Indonesia, sekolah- sekolah dengan fokus pengembangan keahlian sepakbola semakin banyak dijumpai. Sekolah dengan format seperti ini biasa dikenal dengan sekolah sepakbola (SSB). Sekolah sepak bola atau SSB ini merupakan jenjang awal seorang pesepakbola untuk mengasah kemampuan mereka sejak usia anak-anak. Anak-anak akan dibekali teknik-teknik dasar serta strategi- strategi dalam bermain sepakbola sesuai dengan kurikulum yang telah dirancang. Anehnya, pertumbuhan sekolah sepakbola ini tidak dibarengi dengan pertumbuhan jumlah atlet atau pemain sepakbola profesional di Indonesia.

Banyaknya jumlah penduduk di Indonesia yang mencapai 250 juta jiwa ternyata belum sebanding dengan pemain sepakbola profesional yang aktif bermain hingga saat ini. Berdasarkan data dari ketua umum PSSI, jumlah pemain sepakbola professional di Indonesia hanya sebanyak 67.000 orang. Hal ini membuat pemain sepakbola profesional di Indonesia hanya mencapai $0.029 \%$ dari total jumlah penduduk di Indonesia. Data ini berbeda jauh dibandingkan dengan negara yang memiliki prestasi maju dalam bidang sepakbola seperti juara dunia 2010 Spanyol yang memiliki 4,1 juta pesepakbola dengan jumlah penduduk 46,8 juta atau 8,7\%. Untuk wilayah Asia Tenggara Negara dengan prestasi bidang sepakbola terbaik yaitu Thailand memiliki 1,3 juta pesepakbola dari 64 juta penduduknya atau 2,03\% (Siahaan, 2017).

Menyikapi problem kurangnya pertumbuhan jumlah pesepakbola professional di Indonesia, banyak lembaga baik pemerintah maupun swasta mencoba untuk mendirikan sekolah-sekolah sepakbola. Sekolah sepakbola diharapkan dapat menjadi solusi untuk mencetak para pesepakbola professional yang berkualitas. Menurut asosiasi sepakbola dunia yakni FIFA, tujuan dari pembinaan usia muda dengan format akademi atau sekolah sepakbola ini adalah menawarkan pelatihan kepada anak muda yang memungkinkan mereka untuk berkembang dalam konteks pendidikan dan olahraga, memberikan kesetaraan struktur organisasi dan pemantauan pemain muda, mengoptimalkan proses pembelajaran dan program pelatihan, dan berfungsi sebagai model untuk struktur pelatihan lainnya (FIFA, 2016).

Berdasarkan dari tujuan-tujuan tersebut terdapat salah satunya adalah pengembangan konteks pendidikan dan olahraga bagi anak muda. Para siswa sekolah sepakbola haruslah mendapatkan akses dan bimbingan agar ke depannya mereka dapat mengembangkan kemampuan mereka, dalam hal ini memiliki aspirasi karier menjadi atlet sepakbola professional.

Studi kasus yang dilakukan peneliti pada 1 orang subjek siswa sekolah sosial olahraga Real Madrid UNY mendapati salah satu problem yaitu rendahnya aspirasi karier siswa. Dalam beberapa sesi wawancara yang dilakukan peneliti, subjek mengaku lebih tertarik untuk menjadi pengusaha. Hal ini dapat menggambarkan rendahnya keinginan siswa untuk menjadi pemain professional yang teredukasi sejak usia muda sehingga aspirasi karier siswa perlu mendapatkan perhatian dalam pembelajaran. Hal serupa juga didapati peneliti pada sekolah sepakbola Persiba, dari 23 subjek siswa penelitian awal terdapat 9 orang yang memiliki aspirasi karier rendah untuk menjadi pemain sepakbola profesional. Dari angket skala aspirasi karier yang diberikan, nilai dari indicator ketetapan hati untuk menjadi pemain profesional dan memiliki strategi untuk mencapai tujuan mendapatkan skor yang kecil, sehingga aspirasi karier siswa sekolah sepakbola Persiba belum maksimal. Dalam jurnalnya, Bindu dan Padmanabhan (2016) mengungkapkan konsep aspirasi karier ini adalah pada ekspektasi atau sikap tujuan individual, sehingga aspirasi karier akan berperan pada bagaimana siswa menentukan pilihan untuk menjadi pemain professional dan bagaimana perkembangan karier pilihan tersebut dalam jangka waktu 
yang panjang. Dengan meningkatnya aspirasi karier diharapkan terlahir pemain sepakbola professional yang memiliki pengalaman pendidikan sepakbola sejak usia dini.

Dalam penelitiannya, Saputra (2015) menemukan bahwa faktor yang mempengaruhi kelancaran pembelajaran olahraga kelas V-VI SD Kembangjitengan 2 Sleman adalah faktor intern dan ekstern. Faktor intern berupa jasmani, psikologi, dan kelelahan, sedangkan faktor ekstern meliputi keluarga, sekolah, dan masyarakat. Dari faktor-faktor yang didapat, atribut psikologis menjadi salah satu faktor yang mempengaruhi kelancaran anak dalam belajar, sehingga pembelajaran dapat berjalan optimal. Atribut tersebut dapat berupa motivasi, efikasi diri, harga diri dan lain sebagainya.

Salah satu komponen psikologis yang sangat penting dalam kehidupan manusia adalah efikasi diri. Menurut Bandura, 1997 (dalam Cherian \& Jacob, 2013) kesuksesan dalam suatu bidang berhubungan erat dengan efikasi diri. Seseorang akan mempu untuk menggunakan potensi dalam dirinya secara optimal memiliki efikasi diri yang mendukungnya. Namun pada kenyataannya, tidak sedikit orang yang kurang memiliki efikasi diri di dalam dirinya sehingga ia kurang mencapai hasil yang optimal saat melakukan aktivitasnya. Sebagai contoh, seorang atlet tenis lapangan yang memiliki potensi yang tinggi di dalam dirinya akan sulit untuk mencapai hasil yang optimal apabila ia tidak memiliki efikasi diri yang mendukung potensi tersebut (Safitri \& Masykur, 2017). Apabila potensi dalam diri tersebut tidak terakomodasi secara optimal maka cita-cita untuk menjadi pemain profesional menjadi terhambat. Hal ini dikarenakan untuk menjadi pemain profesional dituntut dapat memaksimalkan potensi, sehingga dapat menorehkan prestasi.

Dalam teorinya, Bandura menyebutkan empat proses yang dapat membentuk efikasi diri. Keempat proses tersebut adalah Cognitive Processes, Motivational Processes, Affective Processes, dan Selection Processes (Bandura, 1994). Dalam keempat proses tersebut terdapat proses motivasi atau motivational processes. Proses motivasi ini akan membimbing seseorang untuk berperilaku dan menetapkan tujuan serta membuat rencana untuk menggapai tujuan tersebut. Perilaku menetapkan tujuan merupakan salah satu hasil dari minat seorang individu.

Pemikiran tersebut sejalan dengan hasil penelitian yang dilakukan oleh Bandu dan Padmanaban (2016) yang mendapati adanya hubungan yang signifikan antara efikasi diri dan aspirasi karier di Sekolah Menengah Atas Ernakulam. Berdasarkan hal tersebut perlu dilakukan pembuktian asumsi bahwa efikasi diri dapat mempengaruhi aspirasi karier siswa sekolah sepakbola. Oleh karena itu, penelitian ini bertujuan untuk (1) mengetahui tingkat efikasi diri siswa Sekolah Sepakbola Persiba, (2) mengetahui tingkat aspirasi karier siswa Sekolah Sepakbola Persiba, (3) mengetahui pengaruh efikasi diri terhadap aspirasi karir siswa sekolah sepak bola untuk menjadi pemain sepakbola profesional.

Dengan mengetahui apakah efikasi diri dapat memengaruhi aspirasi karier siswa untuk menjadi pemain sepakbola profesional, maka hasil tersebut dapat membantu tim pelatih untuk menyusun program latihan agar siswa dapat meningkatkan aspirasi karier mereka. Hal ini menjadi arti penting dari penelitian, karena bertambahnya jumlah pemain sepakbola profesional di Indonesia dapat memberikan banyak opsi bagi tim Nasional untuk merekrut pemain. Selain itu, banyaknya jumlah pemain profesional juga akan meningkatkan persaingan antar mereka yang berimbas pada peningkatan kualitas individu. Pada akhirnya sepakbola Indonesia akan dapat berbicara banyak pada kejuaraankejuaraan yang akan diikutinya.

\section{Metode Penelitian}

\section{Jenis Penelitian}

Penelitian ini menggunakan pendekatan kuantitatif.

Waktu dan Tempat Penelitian

Penelitian ini dilakukan pada bulan Februari 
sampai bulan Maret 2019. Penelitian dilaksanakan di Sekolah Sepakbola Persiba Sewon Bantul.

\section{Populasi dan Sampel Penelitian}

Pada penelitian ini yang menjadi subjek penelitian adalah seluruh siswa sekolah sepakbola Persiba usia 12 sejumlah 55 orang. Dari 55 orang subjek siswa sekolah sepakbola Persiba terdapat empat orang subjek yang tidak digunakan dikarenakan kurangnya kelengkapan pengisian data dari angket yang diberikan. Dalam hal ini total subjek yang digunakan dalam penelitian ini adalah 51 orang. Dengan demikian penelitian ini dapat diketegorikan sebagai penelitian populasi.

\section{Data, Instrumen, dan Pengumpulan Data Pengumpulan data pada} penelitian ini menggunakan pengukuran dan alat ukur yang digunakan adalah skala psikologis. Skala yang disusun berupa skala efikasi diri dan skala aspirasi karier.

Skala efikasi diri disusun berdasarkan indikator yang dikemukakan Bandura (dalam Eggen \& Kauchak, 2016) yaitu menerima tugas yang lebih menantang, mengerahkan lebih banyak usaha, bertahan lebih lama, menggunakan strategi yang lebih efektif, dan secara umum berkinerja lebih baik. Dalam penelitian ini, indikator tersebut akan disesuaikan dengan kegiatan belajar di sekolah sepak bola.

Skala aspirasi karier akan disusun berdasarkan aspek-aspek aspirasi karier menurut Litzky (dalam Greenhaus \& Callahan, 2006) yaitu konsep aspirasi karier merupakan sebuah harapan atau suatu bentuk tujuan yang meliputi niat, sikap, dan perilaku. Skala aspirasi karier pada penelitian ini akan disusun berdasarkan

indikator yang berasal dari aspek-aspek aspirasi karier itu sendiri.

\section{Teknik. Analisis Data}

Teknik analisis data yang digunakan dalam penelitian ini terdiri atas analisis deskriptif, uji prasyarat analisis yang terdiri dari uji normalitas dan uji linearitas, serta uji hipotesis.

\section{Analisis Deksriptif}

Data yang berupa angket diperoleh dari kategori yaitu pilihan yang tinggi (4) = sangat sesuai $=$ sangat tinggi, $(3)=$ sesuai = tinggi, $(2)=$ tidak sesuai $=$ rendah,$(1)$ $=$ sangat tidak sesuai $=$ sangat rendah. Kategori dari sangat tinggi sampai sangat rendah akan diubah dalam data interval dengan menggunakan perhitungan manual.

2. Uji Prasyarat

a. Uji Normalitas

Uji normalitas bertujuan untuk mengetahui apakah data yang diambil berasal dari populasi yang berdistribusi normal atau tidak (Noor, 2011). Pengujian ini akan menggunakan program SPSS for windows dalam bentuk Shapiro-Wilk dengan taraf signifikansi $5 \%$ atau 0,05. Pengujian ini akan dilakukan pada nilai residual dari Y. Yakni selisih dari $\mathrm{Y}$ yang merupakan hasil persamaan regresi. Data akan berdistribusi normal apabila memiliki taraf signifikansi $\geq 0,05$, sebaliknya data yang tidak berdistribusi normal akan memiliki taraf signifikansi $\leq$ 0,05 .

b. Uji Linearitas

Pengujian ini digunakan untuk mengetahui apakah antara variabel bebas dan variabel tergantung bersifat linear atau tidak (Noor, 2011). Pengujian ini akan menggunakan program SPPS for windows dengan cara melihat nilai signifikansi dan nilai F. Data akan bersifat linear apabila diperoleh nilai deviation from 
linearity sig. $>0.05$ dan diperoleh nilai $\mathrm{F}$ hitung $<$ dari nilai $\mathrm{F}$ tabel.

3. Uji Hipotesis

Pengujian hipotesis dilakukan dengan menggunakan bantuan IBM SPSS Statistics 22 for windows dengan teknik uji regresi sederhana. Regresi sederhana digunakan untuk menguji ada tidaknya pengaruh variabel bebas terhadap variabel tergantung. Selanjutnya, untuk mencari persamaan garis regresi linear sederhana, menggunakan $\mathrm{Y}=$ $\mathrm{a}+\mathrm{b} \cdot \mathrm{X}$

\section{Hasil Penelitian dan Pembahasan}

Pada penelitian didapati bahwa terdapat pengaruh positif yang signifikan antara efikasi diri terhadap aspirasi karier. Berdasarkan data penelitian yang dianalisis dilakukan pembahasan dari hasil penelitian sebagai berikut:

\section{Efikasi diri siswa sekolah sepakbola Persiba}

Hasil dari penelitian ini menunjukkan bahwa efikasi diri dari 51 subjek siswa sekolah sepakbola Persiba 4 orang masuk dalam kategori sangat rendah, 10 orang masuk dalam kategori rendah, 26 orang berada dalam kategori sedang, 5 orang berada dalam kategori tinggi, dan 6 orang berada berada dalam kategori sangat tinggi. Subjek yang memiliki tingkat efikasi diri yang rendah ditunjukkan dengan pengalaman kegagalan yang dialami subjek, seperti hasil dalam Turnamen Asprov PSSI DIY 2019 yang tidak sesuai dengan target. Hal ini sejalan dengan pendapat Bandura (dalam Feist \& Feist, 2010) yang mengemukakan bahwa salah satu faktor yang dapat memengaruhi efikasi diri adalah faktor pengalaman dalam menguasai sesuatu. Subjek yang memiliki tingkat efikasi diri yang tinggi ditunjukkan dengan adanya role model mereka yaitu pemain sepakbola professional Indonesia yang berhasil menjadi bagian dari Tim Nasional
Indonesia. Model sosial merupakan salah satu faktor yang dapat memengaruhi efikasi diri (Bandura, dalam Feist \& Feist, 2010).

Tingkat aspirasi karier siswa sekolah sepakbola Persiba

Hasil dari penelitian ini menunjukkan bahwa aspirasi karier dari 51 subjek siswa sekolah sepakbola Persiba 3 orang masuk dalam kategori sangat rendah, 10 orang masuk dalam kategori rendah, 21 orang berada dalam kategori sedang, 11 orang berada dalam kategori tinggi, dan 5 orang berada dalam kategori sangat tinggi.

Subjek yang memiliki tingkat aspirasi karier yang rendah ditunjukkan dengan adanya pengalaman kegagalan yang dialami subjek di masa lampau, yaitu hasil dalam Turnamen Asprov PSSI DIY 2019 yang tidak sesuai dengan target. Hal ini sesuai dengan pendapat Hurlock (1999) yang menyatakan bahwa pengalaman masa lampau dapat memengaruhi aspirasi karier seseorang. Subjek yang memiliki tingkat aspirasi karier yang tinggi ditunjukkan dengan adanya ketertarikan atau minat subjek untuk menjadi pemain sepakbola profesional. Selain itu, terdapat pengakuan dari orang tua subjek yang mengatakan bahwa mereka menginginkan anaknya untuk menjadi pemain sepakbola yang sukses. Hal-hal tersebut sesuai dengan pernyataan yang dikemukakan oleh Hurlock (1999) yang menyatakan bahwa minat subjek dan ambisi orang tua dapat memengaruhi aspirasi karier pada seseorang.

\section{Pengaruh Efikasi Diri terbadap Aspirasi Karier}

Berdasarkan hasil penelitian yang telah dilakukan memperoleh analisis bahwa terdapat pengaruh yang positif dan signifikan efikasi diri terhadap aspirasi karier siswa untuk menjadi pemain sepakbola professional. Hal ini seperti pandangan Bandura (dalam Yusuf, 2011) semakin kuatnya keyakinan kemampuan diri yakni efikasi diri seorang individu, maka individu tersebut akan mewujudkannya 
dalam bentuk niat yang kuat, sikap yang tegas, dan perilaku yang gigih yang merupakan aspirasi karier. Oleh karena itu, penelitian ini sejalan dengan penelitian dari Sifah (2015) tentang efikasi diri dan aspirasi karier siswa kelas X SMAN Depok Sleman Yogyakarta, dimana efikasi diri berpengaruh terhadap aspirasi karier secara positif dan signifikan. Hasil ini juga sesuai dengan pendapat Bandura, 1997 (dalam Cherian \& Jacob, 2013) bahwa kesuksesan dalam suatu bidang berhubungan erat dengan efikasi diri. Sebagai contoh dalam penelitian yang dilakukan Safitri dan Masykur (2017) bahwa seorang atlet tenis lapangan yang memiliki potensi yang tinggi akan kesulitan mencapai hasil yang optimal apabila tidak memiliki efikasi diri yang mendukung potensi tersebut.

Besaran pengaruh yang telah didapati ditunjukkan oleh uji $\mathrm{F}$ dengan besaran nilai signifikansi $(\alpha) 0,000 \quad(p<$ $0,05)$. Sumbangan efektif variabel efikasi diri sebesar 51,5\% terhadap aspirasi karier subjek siswa sekolah sepakbola Persiba. Selebihnya $48,5 \%$ dipengaruhi oleh faktor lain yang tidak dilakukan dalam penelitian ini. Faktor-faktor aspirasi karier menurut Hurlock (1999) adalah faktor pribadi dan faktor lingkungan. Faktor pribadi meliputi intelegensi, minat pribadi, pengalaman, pola dan nilai kepribadian, jenis kelamin, kompetisi, hingga latar belakang ras. Faktor lingkungan meliputi ambisi orang tua, harapan sosial, dorongan keluarga, urutan kelahiran, tradisi budaya, nilai sosial, dan media massa.

Dari penjelasan tersebut maka dapat disimpulkan bahwa ada pengaruh efikasi diri terhadap aspirasi karier siswa sekolah sepakbola Persiba Sewon, Bantul. Oleh karena itu, variabel efikasi diri dapat dikatakan sebagai prediktor bagi aspirasi karier siswa sekolah sepakbola Persiba Sewon Bantul tersebut.

Hal tersebut bermakna bahwa semakin kuat efikasi diri seseorang individu, maka individu tersebut akan mewujudkan aspirasi kariernya dalam bentuk niat yang kuat, sikap yang tegas, dan perilaku yang gigih

\section{Simpulan dan Saran}

\section{Simpulan}

Berdasarkan penelitian yang sudah dilakukan, dapat di ambil kesimpulan bahwa:

1. Efikasi diri siswa sekolah sepakbola Persiba, 4 siswa berada pada kategori sangat rendah, 10 rendah, 26 sedang, 5 tinggi, 6 sangat tinggi.

2. Aspirasi karier siswa sekolah sepakbola Persiba 3 berada pada kategori sedang, 10 rendah, 21 sedang, 11 tinggi, 5 sangat tinggi.

3. Terdapat pengaruh yang positif dan signifikan efikasi diri terhadap aspirasi karir.

Hal ini berarti bahwa apabila efikasi diri menunjukkan kategori tinggi, maka aspirasi karier menunjukkan hasil yang cenderung tinggi pula. Apabila efikasi diri menunjukkan kategori rendah, maka aspirasi karier menunjukkan hasil yang cenderung rendah pula.

\section{Saran}

1. Bagi Subjek

penelitian ini dapat memberikan informasi agar meningkatkan efikasi diri, sehingga membantu meningkatnya aspirasi karier untuk menjadi pemain sepakbola profesional

2. Bagi staff pelatih sekolah sepakbola, hasil penelitian ini menunjukkan bahwa meningkatnya efikasi diri akan menjadi prediktor bagi meningkatnya aspirasi karier untuk menjadi pemain sepakbola profesional pada siswa. Sekolah sepakbola diharapkan dapat memberikan fasilitas peningkatan efikasi diri siswa-siswanya melalui materi pelatihan-pelatihan psikologis agar dapat menelurkan pemain-pemain sepakbola profesional kedepannya

3. Bagi penelitian selanjutnya, diperlukan penelitian mengenai variabel efikasi diri maupun aspirasi karier yang memiliki 
jumlah sampel lebih banyak dan cakupan generalisasi yang lebih luas.

\section{Daftar Pustaka}

Azwar, S. (2007). Metode penelitian. Yogyakarta: Pustaka Pelajar.

Bandura, A. (1994). Self-efficacy. California:Academic Press Stanford University.

Cherian, Jacob \& Jacob, Jolly. (2013). Impact of self efficacy on motivation and performance of employees. International Journal of Bussines and Management, 8(14)

FIFA. (2016). Youth football. Zurich: Galledia AG.

Noor, Juliansyah. (2011). Metodologi penelitian: skripsi, thesis, disertasi, dankarya ilmiah. Jakarta: Kencana.

Hurlock, E. B. (1999). Perkembangan anak jilid 2. Jakarta: Erlangga.

Greenhaus, Jeffrey. H \& Callahan, Gerard. (2006). Encyclopedia of career development. California: SAGE Publications, Inc. Volume 1.

Permana, Hara dkk,. (2016). Hubungan antara efikasi diri dengan kecemasan dalam menghadapi ujian pada siswa kelas IX di Mts Al Hikmah Brebes. Jurnal Hisbah, 13(1).

Safitri, D.P. \& Masykur, A.M. (2017). "Hubungan efikasi diri dengan kecemasan menghadapi kejuaraan nasional pada atlet tenis lapangan pelti Semarang". Jurnal Empati, 6(2)

Saputra, A. (2015). Faktor-faktor yang mempengarubi kelancaran pembelajaran penjasorkes kelas V-VI di SD Negeri Kembangjitengan 2 Sleman. Yogyakarata: Universitas Negeri
Yogyakarta.

Siahaan, Michael. (2017). PSSI: Jumlah pesepake bola indonesia sangat sedikit.Diakses tanggal 15

November 2018

https://m.antaranews.com/berita/ 609 151/pssi-jumlah-pesepak-bolaindonesia- sangat-sedikit

Widiastuti, N. (2017). Aspirasi karir siswa SMA berdasarkan status sosial ekonomi dan gender. Indonesia Journal of Educational Counseling 1, (2). 